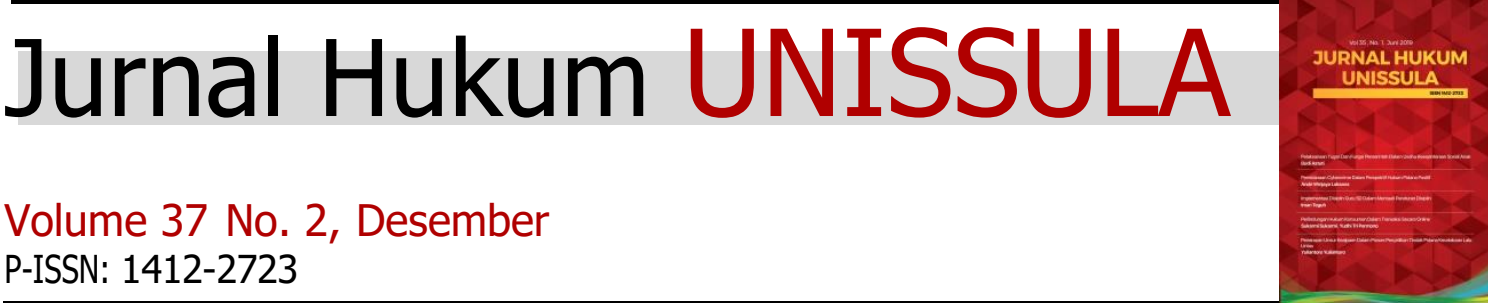

\section{DAMPAK PEMISAHAN KEWENANGAN ANTARA MAHKAMAH KONSTITUSI DAN MAHKAMAH AGUNG DALAM MENGINTERPRETASIKAN UNDANG-UNDANG DAN PERATURAN DI BAWAHNYA}

\section{Chandra Yusuf}

Sekolah Pascasarjana Universitas YARSI, E-mail: chandra.yusuf@yarsi.ac.id

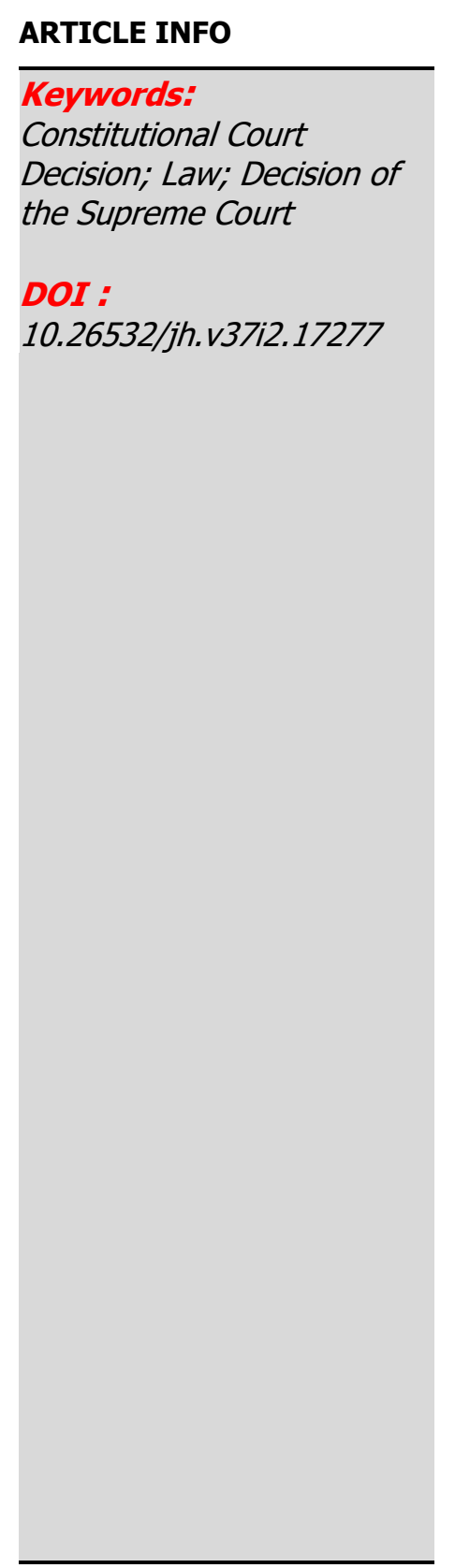

\begin{abstract}
Mahkamah Konstitusi (MK) telah menyediakan dissenting opinion bagi hakim MK yang tidak menyetujui pendapat hakim MK mayoritas. Tetapi permasalahannya hakim yang berbeda pendapat tersebut wajib menandatangani putusan hakim MK mayoritas, dibawah pernyataan pengambilan putusan berdasarkan musyawarah yang jelas tidak mewakili pendapatnya sendiri. Tujuan penelitian ini adalah untuk mengatasi perbedaan interpretasi UU yang dibuat oleh MK maupun Mahkamah Agung (MA) terhadap UU. Penelitian merupakan penelitian hukum normatif, dengan menggunakan data berupa bahan hukum primer, bahan hukum sekunder dan bahan hukum tersier, yang diunduh melalui website. Analisa data dilakukan secara kualitatif dan pemaparannya dilakukan dengan deskriptif analisis. Hasil penelitian menunjukkan bahwa: pertama, perbedaan pendapat hakim MK tidak dapat diselesaikan dengan musyawarah dan dissenting opinion, karena sistem civil law berbeda dengan common law yang memiliki preseden. Kedua, perbedaan pendapat hakim MK akan mempengaruhi interpretasi UU yang juga menjadi kewenangan MA sebagai lembaga yang dapat menguji peraturan perundang-unadangan dibawah UU, sehingga cara yang terbaik dengan mewajibkan putusan MK sebagai rujukan $M A$.
\end{abstract}

The Constitutional Court (MK) has provided a dissenting opinion for MK judges who do not agree with the majority judge's opinion. But the problem is that judges of differing opinions must sign the decision of the majority of the Constitutional Court justices, under the statement of decision-making based on deliberation that clearly does not represent his opinion. The purposed of this study is to overcome the differences in the interpretations of the Law made by the Constitutional Court and the Supreme Court (MA). This article was composed of the results of normative legal research using secondary data in the form of primary legal materials, secondary legal materials and tertiary legal materials, which are downloaded through the website. Data analysis was carried out qualitatively and the presentation was carried out with descriptive analysis. This article has two conclusions: First, the difference of opinion of the Constitutional Court judges cannot be resolved by deliberation and dissenting opinion, because the civil law system is different from the 
common law that has a precedent. Second, the difference of opinion of the Constitutional Court judges will affect the interpretation of the laws which is also the authority of the Supreme Court as an institution that can examine the laws and regulations under the laws, so that the resolution requires the Constitutional Court's decision as a Supreme Court reference.

\section{A. PEndahaluan}

Pemisahan kekuasaan negara dikenal sebagai Trias Politica membagi kekuasaan negara menjadi 3 (tiga) bagian, yakni Executive, Legislative dan Judicative dalam tulisan dari CharlesLouis de Secondat, baron de La Brède et de Montesquieu, dan karyanya, The Spirit of Laws (1748). ${ }^{1}$ Executive dan Legislative memiliki produk hukum. Judicative dapat menguji produk hukum dari Legislative yang menyimpang dari Constitution dan juga menguji peraturan Executive yang melanggar produk hukum Legislative. Judicative menempatkan posisinya sebagai wasit di dalam pemisahan kekuasaan negara melalui putusan yang mengikat. Putusan hakim tersebut mengikat berdasarkan asas preseden dalam sistem Common Law. Namun lembaga Judicative yang menguji UU dan dan peraturan dibawah UU berbeda.

$\mathrm{Di}$ Indonesia, Undang-Undang (UU) disahkan oleh Dewan Perwakilan Rakyat (DPR) masuk dalam kekuasaan Legisitative. Sedangkan peraturan dibawah UU dibuat oleh presiden dan lembaga dibawahnya, masuk dalam kekuasaan Executive. UU sebagai produk DPR, apabila bertentangan dengan Undang-Undang Dasar (UUD) 1945 dapat diuji melalui Mahkamah Konstitusi (MK). Motivasi pengujian terhadap UU, karena hak individu yang dilindungi oleh UUD tidak diakomodir dalam UU tersebut. Dasar hukum dari pengujiannya adalah seluruh UU harus sesuai dengan interpretasi UUD 1945.

Dalam mengatasi permasalahan peraturan dibawah UU yang melanggar UU akan diuji oleh Mahkama Agung (MA). Dalam posisi yang demikian, MK memiliki kekuasaan yang lebih besar karena kewenangannya untuk melakukan pengujian terhadap UU. Namun MK dan MA memiliki hirarkhie kewenangan berbeda untuk melakukan pengujian terhadap peraturan perundang-undangan.

Seperti negara demokrasi lainnya, Indonesia telah mengikuti perkembangan terkini dari pemisahan kekuasaan negara. Saat ini negara di dunia telah memasuki era Judicial Review (JR) yang dapat diungkapkan: ${ }^{2}$

The late 20th and early 21st centuries may well be marked as the Judicial Era. Courts have burgeoned across the globe. With this turn to judicial power has come the rise of judicial review-a court's review of a legislative or executive act for constitutional compliance.

Peraturan Judicative dan Executive dapat menyimpang dari

1 Jasna Omejec, Principle of the Separation of Powers and the Constitutionla Justice System, https://bib.irb.hr/datoteka/785200.Omejec_-

_Separation_of_Powers_and_Constitutional_Judiciary_-_Strasbourg_28.10.pdf, diunduh pada tanggal 24 November 2019.

2 Erin F Delaney and Rosalind Dixon, (Edited), Tom Ginsburg (Ed), Comparative Judicial Review, Cheltenham, Uk dan Northampton, MA, Edward Elgar Publishing Limited, USA, 2018, hlm. 1. 
konstitusi, yang diperbaiki melalui JR. Pendapat hakim MK dapat mengatasi penyimpangan tersebut. Kelompok hakim MK dengan suara terbanyak akan menerima atau menolak permohonan JR. Pendapat Hakim MK yang tidak sesuai dengan pendapat utama akan dikesampingkan. Putusan MK akan terfokus pada pendapat hakim MK yang dapat dimusyawarahkan atau pendapat dengan suara terbanyak. Pasal dalam UU atau UU secara keseluruhan diuji berdasarkan pendapat hakim MK dengan menginterpretasikan UU dan UUD 1945. Selama ini, Indonesia belum memiliki interpretasi yang baku sebagai penjelasannya, sehingga hakim MK dapat memiliki pendapat berbeda atas interpretasi dari UU dan UUD 1945. Peristiwa yang mungkin terjadi dari pendapat hakim MK adalah pendapat kelompok yang menerima dan menolak. Putusan hakim MK akan mempengaruhi interpretasi UU yang akan digunakan oleh MA dalam melakukan pengujian terhadap peraturan dibawah UU.

Perlunya jumlah 9 (sembilan ) hakim MK untuk membantu para hakim MK mengambil putusan, sehingga penyelesaiannya dilakukan dengan voting, apabila musyawarah tidak tercapai. Untuk mengatasi jalan buntu, hakim MK harus melakukan voting dengan suara terbanyak agar pendapat hakim MK mayoritas yang menjadi dasar hukum putusannya. Namun perbedaan pendapat hakim MK tersebut tidak mungkin dapat dikesampingkan dengan pilihan suara terbanya. Kualitas dari pendapat hakim MK juga harus mendapat penilaian. Karena itulah, pendapat hakim MK yang memiliki suara minoritas tetap wajib dituangkan kedalam bentuk tertentu.

Permasalahan yang timbul adalah apabila hakim MK berbeda pendapat atas interpretasi UU yang akan diuji dan interpretasi dari UUD 1945 itu sendiri. Sementara MA memiliki hak yang sama dengan MK dalam menginterpretasikan UU. Apabila MK dan MA memiliki perbedaan pendapat dalam menginterpretasikan UU, maka peraturan dibawah UU akan menjadi tidak konsisten. UU dan peraturan dibawahnya tidak akan sejalan dengan UUD 1945. Perbedaan interpretasi UU akan memisahkan UUD 1945 dari UU dan peraturan dibawahnya. MK memerlukan kewenangan untuk mengenyampingkan interpretasi MA terhadap UU. Artinya hakim MA harus merujuk kepada putusan MK, bukan UU.

Adapun Moh Mahfud, MD dalam artikel yang berjudul: Titik Singgung Wewenang $M K$ dan $M A$, yang telah dibuat sebelumnya tentang putusan MK yang final and binding. Ia membahas tentang adanya persilangan kewenangan MK yang mengadili konflik peraturan yang bersifat abstrak sekaligus mengadili konfliks atau sengketa antara orang atau lembaga yang bersifat kongkrit, demikian pula MA mengadili konflik atau sengketa antara orang atau lembaga yang bersifat kongkrit, dan mengadili konflik peraturan yang bersifat abstrak. Keduanya baik MK dan MA memiliki kewenangan yang sama, akan tetapi memiliki tingkat yang berbeda. ${ }^{3}$ Adanya penulis lainnya M. Agus, Maulidi dalam artikelnya yang berjudul: Menyoal Kekuatan Eksekutorial Putusan Mengikat Mahkamah Konstitusi,

3 Moh Mahfud, MD, Titik Singgung Wewenang MK dan MA, Jurnal Hukum dan Peradilan, Vol.4, No.1, Maret 2015 
juga membahas tentang kemampuan eksekutorial dari putusan MK yang harus dilaksanakan dengan intrumen hukum baru dan putusan MK memerlukan jeda waktu untuk membentuk instrumen hukum baru agar dapat dilaksanakan putusannya. ${ }^{4}$ Sementara Antoni Putra, dalam artikel yang berjudul: Dualisme Pengaturan Undang-Undang, yang membahas tentang perlunya penyatuan kewenangan Judicial Review dalam satu atap sehingga penegakan Konstitusi secara integral di dalam peraturan perundang-undangan tercapai. ${ }^{5}$

Dalam hal ini penulis membahas tentang dualisme dari pengaturan Undang-Undang yang diselesaikan dengan asas preseden. Perbandingan proses putusan dengan sistem hukum yang berbeda antara Indonesia dan Amerika Serikat dalam menemukan apa yang menjadi putusan Supreme Court terintegrasi secara keseluruhan karena sifat putusan sengketa anatar orang dan institusi yang bersifat kongkrit dan sekaligus peraturan yang bersifat abstrak dalam satu putusan Supreme Court yang sekaligus memayungi seluruh perbedaannya.

\section{B. METODE PENELITIAN}

Metode yang digunakan dalam penelitian ini adalah penelitian hukum normatif, yang dapat dibagi menjadi dua, yakni primary source dan secondary source, yang diuraikan. Sementara sumber primer adalah teks undang-undang itu sendiri, sumber sekunder adalah dokumen yang menafsirkan atau membahas sumber primer. Ini mungkin termasuk jurnal, artikel, surat kabar, posting online, dan sebagainya. ${ }^{6}$

Penelitian hukum dilakukan dengan perbandingan sistem hukum dengan objek proses putusan di tingkat MK dan Suprem Court di Amerika Serikat (AS). Materinya diperoleh dari studi kepustakaan, online di internet dengan menganalisis suatu permasalahan hukum di tingkat putusan MK berdasarkan peraturan perundang-undangan, literatur-literatur dan bahanbahan referensi lainnya yang berhubungan dengan judul penelitian sebagai bahan analisis, yang secara deskriptif dipergunakan untuk menggambarkan apa yang terjadi di MK dan MA terhadap obyek yang diteliti dengan pendekatan kualitatif, dipersandingkan secara prescription dengan menggunakan pendekatan kausal komparatif berdasarkan ilmu hukum agar memperoleh gambaran atau pedoman mengenai prosedur yang tepat dalam menjelaskan proses putusan MK. Peneliti menggambarkan prosedur dan proses pengambilan putusan hakim Supreme Court di AS yang berdasarkan Common Law yang kemudian dibandingkan dengan proses pengambilan putusan hakim MK di Indonesia. Peneliti mencari kesamaan dalam prosesnya dan menemukan apa yang menimbulkan perbedaan atas hasilnya, karena sistem hukum dengan keputusan Supreme Court yang

4 M. Agus, Maulidi, Menyoal Kekuatan Eksekutorial Putusan Mengikat Mahkamah Konstitusi, Jurnal Konstitusi, Vol.16, No.2, Juni 2021

5 Antoni Putra, Dualisme Pengaturan Undang-Undang, Jurnal Legislasi Indonesia, Vol.15 No.2, Juli 2018

6 Cara O'Neill, (Ed), Legal Research, How To Find and Understand Law, The Nolo, USA, 2018, hal. 24 
menjadi satu dan terintegrasi dengan keputusan MK yang terpisah dengan putusan MA.

\section{PEMBAhASAN}

\section{Jumlah Hakim MK}

Mahkamah Konstitusi (MK) memiliki jumlah hakim ganjil yang terdiri 9 (sembilan) orang. Pemilihan angka ganjil ini bukan tanpa maksud. Dalam numerik angka ganjil menyisakan 1 (satu) dibandingkan angka genap sebelumnya. Apabila jumlah ganjil tersebut dibagi 2 (dua) kelompok, maka agar pembagian angka menjadi bulat, salah satu kelompok akan mendapat kelebihan 1 (satu) suara. Saat putusan tidak mencapai kesepakatan, maka voting menjadi cara yang terbaik untuk menyelesaikannya. Untuk mencapai suara hakim yang dibutuhkan dalam mencapai kesepakatan hakim, seharusnya seluruh hakim menghadiri persidangan. Kelebihan 1 (satu) suara hakim menjadikan 1 (satu) kelompok hakim yang berpendapat memiliki suara terbanyak. Pendapat utama kelompok hakim tersebut dianggap kelompok majoritas yang memembuat putusan utama.

Kesamaan dari pengaturan jumlah hakim MK dapat dilihat dari sejarah penentuan jumlah hakim Supreme Court di Amerika. Konstitusi AS yang asli tidak menetapkan jumlah hakim di Mahkamah Agung. Oleh karena itu, terserah kepada kongres untuk memutuskannya. Kongres menetapkan 5 (lima) hakim, dan pada tahun 1801. Tetapi jumlah tersebut tidak berlangsung lama. Kongres meningkatkan jumlah hakim menjadi 7 (tujuh) pada tahun 1807, dan menjadi 9 (sembilan) pada tahun 1837, kemudian menjadi 10 (sepuluh) pada tahun 1863. Kemudian, untuk mencegah Presiden Andrew Johnson, yang akan segera dimakzulkan, agar tidak menunjuk hakim Supreme Court yang baru, kongres meloloskan the Judicial Circuits Act of 1866. Peraturan ini mengurangi jumlah hakim dari 10 (sepuluh) menjadi 7 (tujuh). Penurunan ini mulai berlaku karena kursi hakim Supreme Court kosong, sehingga tersisa dua kursi kosong pada tahun 1869. Ada 8 (delapan) hakim yang masih tersisa dalam Supreme Court. Kongres menambahkan 1 (satu) kursi kembali dan memutuskan bahwa harus ada 9 (sembilan) hakim. Adanya the Judiciary Act of 1869 secara resmi menetapkan jumlah hakim menjadi 9 (sembilan), dan sejak itu belum berubah angkanya. $^{7}$

Lebih dari 600 hakim berada di pengadilan distrik, hampir 200 hakim duduk di pengadilan banding, dan 9 hakim membentuk Supreme Court. Karena semua hakim federal memiliki masa kerja, presiden tidak dapat membuat penunjukan terhadap hakim Supreme Court. Tetapi banyak lowongan yang terjadi selama masa jabatan presiden. Jadi, keadaan tersebut menunjuk hakim bisa menjadi pekerja penuh waktu. Seorang presiden bergantung pada banyak sumber untuk merekomendasikan calon yang tepat untuk jabatan hakim. Calon yang

7 Life Science, Why Are There 9 Supreme Court Justices?, https://www.livescience.com/9857-9supreme-court-justices.html, diunduh pada tanggal 25 November 2019. 
diajukan wajib memenuhi syarat: pengalaman, ideologi politik, partai dan loyalitas pribadi, jenis kelamin dan etnisitas. ${ }^{8}$ Penunjukkan presiden terhadap hakim Supreme Court di Amerika tersebut tersebut tidak berbeda dengan penunjukkan presiden tehadap hakim MK di Indonesia.

Hakim Supreme Court Amerika memiliki 9 (sembilan) orang hakim karena sejarah Amerika yang membentuknya demikian. Penurunan yang asalnya dari 10 (sepuluh) orang menjadi jumlah 9 (sembilan) orang diakibatkan permasalaham keuangan. Jumlah yang terakhir menjadi jumlah permanen dalam pertaurannya. Permanen dalam pengertian jumlah hakim Supreme Court tidak mengalami perubahan lagi. Saat peraturan dibuat jumlah tersebut yang menjadi dasarnya. Hakim MK juga mengikuti jumlah yang sama dengan jumlah hakim Supreme Court di Amerika. Kekosongan hakim MK akan diisi melalui seleksi yang sama dengan kriteria yang wajib dipenuhi dalam penentuan calon hakim Supreme Court Amerika.

Tindakan demikian tidak memiliki alasan yang rasional. Keputusannya hanya karena Supreme Court Amerika yang memiliki jumlah 9 (sembilan) orang hakim. Padahal jumlah hakim tersebut terbentuk karena sejarah masyarakatnya. Karena itu MK hanya melakukan tindakan yang buta taklik. Pembuat UU tidak melihat esensi dari penentuan jumlah hakim dan reasoning-nya. Seharusnya jumlah hakim 9 (sembilan) ditujukan untuk melakukan voting sehingga jumlah ganjil suara menghindari pengambilan putusan seimbang. Dalam kasus yang akan diputus, cases transgender rights and Republican-backed state laws that opponents contend were designed to suppress the turnout of black, Hispanic and other voters who tend to back Democrats potentially could be added to the docket, although those cases could lead to 4-4 ties. ${ }^{9}$ Dalam voting keadaan menang-menang (win-win solution) tidak pernah terjadi. Salah satu kelompok harus memiliki suara terbanyak dibandingkan dengan kelompok lainnya agar tercapai suara mayoritas yang berhak membuat pendapat utama.

\section{Ketidakhadiran Hakim MK}

Dalam Undang-Undang (UU), jumlah hakim tersebut dicantumkan dengan jumlah yang sama, yakni 9 (sembilan) orang. Kenyataannya, jumlah 7 (tujuh) orang hakim sekalipun tidak mempengaruhi status dari putusan MK. Pasal 28 ayat (1) UU Nomor: 24 Tahun 2003 tentang Mahkamah Konstitusi menyebutkan: "Mahkamah Konstitusi memeriksa, mengadili, dan memutus dalam sidang pleno Mahkamah Konstitusi dengan 9 (sembilan) orang hakim konstitusi, kecuali dalam keadaan luar biasa dengan 7 (tujuh) orang hakim konstitusi yang dipimpin oleh Ketua Mahkamah Konstitusi."

8 American Government, How Judges and Justices Are Chosen, https://www.ushistory.org/gov/9d.asp, diunduh pada tanggal 27 November 2019.

9 Fortune, The U.S. Supreme Court Will Return with Only 8 Justices, https://fortune.com/2016/09/30/us-supreme-court-justices/, diunduh pada tanggal 28 November 2019. 
Adapun keadaan luar biasa yang dimaksud tercantum dalam penjelasan dari pasalnya: "Yang dimaksud dengan "keadaan luar biasa" adalah meninggal dunia atau terganggu fisik/jiwanya sehingga tidak mampu melaksanakan kewajiban sebagai hakim konstitusi." Alasan yang paling ringan adalah "terganggu fisiknya" sehingga hakim tidak dapat melaksanakan kewajiban yang dipikulnya. Penjelasan yang demikian membuat putusan MK tetap sah, apabila hakim yang hadir tidak mencapai 9 (sembilan) orang. Namun penjelasan dapat mengarahkan pengertian ketentuannya menjauh dari apa yang dimaksud oleh UU. Seberapa valid suatu penjelasan UU sehingga ketentuan yang tercantum dalam UU dapat diinterpretasikan menjauhi dari pengertian denotasi ${ }^{10}$. Hakim yang terkena flu biasa juga termasuk dalam kriteria terganggu fisiknya. Pengecualian tersebut didukung dalam tata acara rapat, pleno dapat diikuti minimal tujuh hakim. ${ }^{11}$ Rapat pleno dihadiri oleh 8 (delapan) hakim yang berjumlah genap, apabila kelompok hakim terbagi dua, maka putusan MK dengan voting tidak mungkin dilakukan.

Ada beberapa kali, presiden mencoba mengajukan calon hakim selama dua tahun terakhir, ketika Supreme Court Amerika memiliki kurang dari sembilan hakim. Pertama, ada celah di 2016 setelah kematian Hakim Agung Antonin Scalia. Pengadilan hanya memiliki delapan hakim agung selama lebih dari setahun karena Demokrat dan Republik memperebutkan apakah pilihan Presiden Barack Obama saat itu akan dikonfirmasi selama tahun pemilihan.

Drama itu berakhir dengan calon Obama, Merrick Garland, yang ditolak audiensi konfirmasi. Pengganti Obama, Presiden Donald Trump, kemudian mencalonkan Neil Gorsuch, yang dikonfirmasi pada April 2017. Lowongan terbaru pengadilan datang setelah hakim Anthony Kennedy mengumumkan bahwa ia akan pensiun musim panas ini, memberikan Trump kesempatan kedua dalam beberapa tahun untuk menunjuk hakim ke kursi hakim. Pada bulan Oktober, Brett Kavanaugh dilantik setelah proses konfirmasi yang kontroversial dan margin suara yang paling sempit dalam lebih dari satu abad. ${ }^{12}$

Penunjukkan hakim Supreme Court di Amerika memiliki kepentingan politik yang sangat besar. Keberpihakan dalam politik akan menentukan pendapat yang diberikan oleh hakim dalam suatu perkara. Kehadiran hakim di persidangan menjadi sangat penting. Pendapat hakim tidak terlalu penting terhadap perkara yang memiliki kepentingan politik, akan tetapi suara dalam voting yang akan dibutuhkan. Perbedaan

10 Kamus Besar Bahasa Indonesia (KBBI), denotasi/de'no'ta'si//dénotasi/ n Ling makna kata atau kelompok kata yang didasarkan atas penunjukan yang lugas pada sesuatu di luar bahasa atau yang didasarkan atas konvensi tertentu dan bersifat objektif, https://kbbi.web.id/denotasi, diunduh pada tanggal 20 Oktober 2019.

11 Kompas, Yusril Pertanyakan Jumlah Hakim Konstitusi, https://nasional.kompas.com/read/2009/02/18/11062555/yusril.pertanyakan.jumlah.hakim.k onstitusi., diunduh pada tanggal 20 Oktober 2019.

12 Meghan Keneally, Meet all of the sitting Supreme Court justices ahead of the new term, https://abcnews.go.com/Politics/meet-sitting-supreme-court-justices/story?id=37229761, diunduh pada tanggal 28 November 2019. 
antara kelompok kepentingan politik dieksploitasi dan terlihat perbedaan yang sangat jelas. Putusan yang dimenangkannya akan mempengaruhi kepentingan penguasa dan pengaruhnya terhadap masyarakat Amerika kedepannya.

Keadaannya berbeda dengan hakim MK di Indonesia. Musyawarah dalam mengambil putusan lebih dipentingkan. Konflik kelompok kepentingan akan terhindar. Namun kelemahan dari musyawarah adalah suara bulat dari seluruh hakim MK dapat mendukung pendapat yang mengukuhkan kepentingan penguasa secara absolut. Untuk menjaga validitasnya, MK memperbolehkan hakim mengutarakan pendapat yang berbeda. Hakim MK yang mengungkapkan pendapat berbobot akan terlihat dalam putusan atau dissenting opinion yang dibuat.

\section{Proses Pengambilan Keputusan}

MK membutuhkan hakim yang berkualitas dalam keilmuannya agar dapat memberikan pendapat yang dapat dipertanggungjawabkan kepada masyarakat. Perbedaan pendapat antar hakim akan terjadi dalam proses pengambilan keputusan. Tentunya perbedaan tersebut wajib diakomodir dalam suatu sistem yang terbuka sehingga seluruh masyarakat juga dapat mengkajinya. Keterbukaan dalam proses pengambilan putusan hakim menjadi dasar yang membentuk kepercayaan masyarakat. Perbedaan pendapat hakim yang memutus perkara dituangkan secara terpisah agar keputusan yang diambil tetap bulat dan utuh. Masyarakat dapat mengetahui perbedaan pendapat yang terjadi dalam proses pengambilan keputusan oleh seluruh hakim.

Dalam tahapan pengambilan keputusan: tahap pertama adalah musyawarah, setiap hakim yang hadir memberikan pendapat sesuai hukum hingga tercapai kesepakatan. Kedua, hakim tidak mencapai kesepakatan dapat diselesaikan melalui musyawarah. Hakim yang melakukan penolakan atas hasil dan alasannya dapat mengajukan dissenting opinion. Sementara hakim yang menyetujui dapat dibagi atas dua bagian, yakni hakim menyetujui seluruhnya, baik hasil maupun reasoning ${ }^{13}$ dan hakim yang menerima hasilnya akan tetapi menolak reasoning yang menjadi dasar hukumnya.

Namun dalam putusan MK yang memiliki dissenting opinion, hakim yang menolak hasil dan reasoning juga termasuk dalam putusan yang berdasarkan musyawarah. Padahal pengambilan keputusan diselesaikan dengan voting, pengambilan suara terbanyak, bukan musyawarah. Masyarakat dapat mengeksaminasi putusan MK. Tentunya, pendapat yang digunakan oleh hakim sebagai dasar hukum dalam membentuk putusan menjadi objek eksaminasi.

13 Tempo.com, Tiga Langkah Bagaimana Putusan MK Dibuat, https://nasional.tempo.co/read/1259803/tarik-ulur-perpu-kpk-ini-3-syarat-perpumenurut-mk, diunduh pada tanggal 20 Oktober 2019. 
Di Amerika Serikat, JR berada dalam satu atap, yakni Supreme Court: ${ }^{14}$ "Article III, Section 1, of the U.S. Constitution states that the "judicial power of the United States shall be vested in one Supreme Court and in such inferior Courts as Congress may from time to time ordain and establish." Pengadilan dibawahnya akan mengikuti putusan hakim Suprem Court atas perkara yang sama, sehingga proses pengadilan di bawahnya tidak berlanjut ke Supreme Court. Pengambilan putusan akan sama di setiap tingkat pengadilan atas perkara yang sama.

Proses pengadilan di tingkat Supreme Court akan mengikuti prosedur yang telah ditetapkan. Setelah semua hakim Supreme Court mendengarkan oral argument dalam perkaranya, maka mereka akan membuat opinion dan reasoning. Hakim ketua yang dalam posisi mayoritas akan meringkas pendapat hakim dalam ruangan berdasarkan jadwalnya. Setelah itu ringkasannya akan diumumkan di website. Pengadilan juga dapat menyidangkan kasus berdasarkan pendapat per curiam, yang tidak mengidentifikasi penulis. Pendapat ini sering menyelesaikan kasus secara ringkas, sering tanpa argumen lisan, tetapi mereka telah diisukan dalam kasus penting yang diperdebatkan, seperti Bush v. Gore, 531 U. S. 98, dan kasus keungan bagi kampanye Buckley v. Valeo, 424 U. S. 1. Pendapat di dalam kamar hakim ditulis oleh seorang hakim secara individual untuk men-dispose aplikasi oleh suatu pihak untuk bantuan sementara, mis., Untuk penundaan putusan pengadilan di bawah ini, untuk liburan, atau untuk perintah sementara.Hakim juga dapat menulis pendapat yang berkaitan dengan perintah Pengadilan, mis., Untuk perbedaan pendapat dari penolakan certiorari atau untuk menyetujui penolakan itu. Semua pendapat kemudian dikompilasi dan dicetak dalam Laporan Amerika Serikat, publikasi resmi Pengadilan. Versi elektronik dari volume terikat diposting di situs web ini. ${ }^{15}$

Seluruh hakim Supreme Court yang hadir dan mendengan argumen pihak pemohon secara lisan (ora). Para hakim Supereme Court akan memberikan pendapat secara pribadi dan melakukan voting dengan suara terbanyak. Pembuatan putusan tas perkara tersebut dalam waktu reses. Hakim ketua yang berada dalam posisi suara terbanyak akan mendapatkan tugas membuat draft putusan. Apabila hakim ketua tidak berada dalam posisi suara terbanyak, maka hakim senior yang akan membuat draft putusan. Seorang hakim Supreme Court yang menjadi ketuanya dan hakim senior akan menunjuk hakim yang akan bertugas menulis pendapat mayoritas. Nantinya hakim tersebut akan mengedarkan putusan dari pendapat mayoritas kepada seluruh hakim Supreme Court. Hakim ketua akan menyebarkan hasil putusan tersebut kepada seluruh hakim Supreme Court. Hakim Supreme Cout yang setuju

14 Ioannis G, Dimitrakopoulos, Individual Rights and Liberties Under the U.S., Constitution The Case Law of the U.S. Supreme Court, Koninklijke Brill NV, Leiden, 2007, hal. 1.

15 Supreme Court of the United States, Opinion, https://www.supremecourt.gov/opinions/opinions.aspx, diunduh pada tanggal 28 November 2019 
dengan pendapat hakim ketua tidak akan memberikan pendapat apapun. Hakim Supreme Court yang setuju dengan hasilnya, akan tetapi tidak setuju dengan alasannya, dapat mengajukan concurring opinion. Namun hakim Supreme Court yang menolak alasan dan hasilnya akan membuat dissenting opinion.

Setelah pendapat berdasarkan suara terbanyak melalui voting, hakim ketua membuat draft putusan. Selanjutnya draft tersebut disirkulasikan kepada hakim lainnya. Dalam proses penulisan opini, hakim memiliki opsi yang beragam. Pertama, hakim dapat mengikuti draft putusan. Kedua, hakim dapat meminta perbaikan tulisan dalam draft putusan. Ketiga, hakim memilih concurrence dengan menerima hasil dan isi dari draft putusannya. Keempat, hakim dapat memilih concurrence dengan menerima hasil, akan tetapi menolak putusan. Kelima, hakim dapat mengeluarkan dissenting opinion. ${ }^{16}$

\section{Musyawarah}

Berdasarkan Kamus Besar Bahasa Indonesia (KBBI), musyawarah memiliki pengertian: ${ }^{17}$ musyawarah/mu'sya'wa'rah/ $\mathrm{n}$ pembahasan bersama dengan maksud mencapai keputusan atas penyelesaian masalah; perundingan; perembukan. Dari pengertiannya, musyawarah tidak menjadi tahapan dalam mengambil putusan dengan voting. Musyawarah tidak menekankan kalah menang dalam meraih suara, akan tetapi rembukan dalam mencapai hasil.

Alasan yang lebih masuk akal adalah musyawarah tidak memerlukan voting suara hakim dalam memutus perkara, sehingga angka ganjil tidak diperlukan dan kehadiran satu atau dua hakim tidak akan mempengaruhi materi putusannya. Apabila hakim yang hadir 8 orang, maka apabila terjadi perbedaan pendapat dan hakim terbelah menjadi 2 (dua) kelompok, keduanya akan melakukan musyawarah yang pada akhirnya menyetujui putusan hakim dari salah satu kelompok. Pengambilan putusan MK berdasarkan musyawarah, buka voting, karena jumlahnya genap. Pengambilan keputusan dengan jumlah genap tersebut menunjukkan hakim MK memang melakukan musyawarah. ${ }^{18} \mathrm{MK}$ tidak mengenal pengambilan keputusan berdasarkan suara terbanyak.

Melihat format putusan MK, hakim melakukan musyawarah terlebih dahulu dalam memutus perkaranya, yang dapat diuraikan

16 Pamela C Corley, Concurring Opinion Writing on the U.S. Supreme Court, SUNY Press, New York, 2010, hal.4.

17 Kamus Besar Bahasa Indonesia, Musyawarah, https://kbbi.web.id/musyawarah, diunduh pada tanggal 22 November 2019.

18 Veri Junaidi, dkk, Membaca 16 Tahun Mahkamah Konstitusi (MK): Data Uji Materi Undang_undang terhadap UUD 1945 (2003-2019), Jakarta: Yayasan Konstitusi Demokrasi Inisiatif, 2019, hal. 5. Ada sejumlah catatan atas pemberlakuan hukum acara pengujian undang-undang terhadap UUD 1945. Pelaksanaan Rapat Permusyawaratan Hakim (RPH) dan rapat pleno yang seharusnya dihadiri 9 orang hakim tidak sepenuhnya lengkap. Terdapat 169 putusan dengan RPH yang dihadiri hanya 8 orang hakim, bahkan terdapat 63 putusan dengan RPH yang hanya dihadiri oleh 7 orang hakim. 
dengan perkataan:19 "Demikian diputus dalam Rapat Permusyawaratan Hakim oleh sembilan Hakim Konstitusi yaitu...". Apabila Rapat Permusyawaratan Hakim (RPH) yang menjadi dasar putusan MK adalah sepakat untuk tidak sepakat, maka seluruh hakim yang hadir memiliki kesepakatan atas pendapat sama yang digunakan dalam pokok putusan, bukan pendapat yang berbeda dari hakim MK. Pendapat hakim MK minoritas yang berbeda akan diberikan kesempatan untuk menuangkan pendapatnya dalam dissenting opinion.

Berbeda dengan sistem hukum common law, dissenting opinion dalam sisitem hukum Indonesia yang berdasarkan civil law, tidak mengikat dan tidak memiliki pengaruh atas putusan setelahnya dalam perkara yang sama. Emlin McClain mengatakan: ${ }^{20}$

"... in some cases dissenting opinions are not only proper, but necessary, and that to suppress the views of those judges whoare unable to agree with the majority of their brethren, would not favor, but would rather obstruct, the harmonious and safe development of the law."

Dalam musyawarah, jumlah ganjil dari hakim tidak dibutuhkan. Kehadiran hakim dengan jumlah genap juga tidak menjadi masalah dalam mengambil putusan. Seluruh hakim wajib menandatangani putusan MK. Kerancuan dari hukum acara MK adalah hakim MK yang tidak sepakat menandatangani putusan utama hakim MK. Hakim MK yang menolak atas putusan utama hanya mengekspresikan kehadirannya adalah kesalahan logika. Hakim MK yang melakukan dissenting opinion tidak seharusnya menandatangani putusan utama. Seperti halnya JR di Amerika Serikat, Hakim ketua dari Supreme Court yang memiliki suara terbanyak atau hakim yang ditunjuk oleh hakim senior karena hakim ketua tidak berada dalam posisi suara terbanyak membuat dan menandatangani putusannya. Hakim lain yang menyetujui tidak melakukan apapun. Sementara hakim yang menerima hasil putusan tetapi tidak menerima alasannya akan diberikan kesempatan untuk menulis pendapatnya (concurring opinion). Hakim yang menolak akan memberikan dissenting opinion, akan tetapi seluruh hakim tidak menandatangani putusan utama, kecuali hakim ketua.

Faktanya, RPH bukan wadah kehadiran dari para hakim MK yang mewakili daftar absensi. RPH adalah wadah untuk merembukkan pendapat sebelum dituangkan kedalam putusan MK. Lain halnya, apabila rembukan pendapat tersebut telah dituangkan dan ditandatangani oleh seluruh hakim MK. Rembukan pendapat tersebut bukan lagi dalam wadah musyawarah, akan tetapi telah menjadi hasil putusan yang disetujui bersama. Sama halnya dengan perjanjian yang ditandatangani. Kalimat yang diuraikan dalam perjanjian disepekati diatasnya dengan

19 Mahkamah Konstitusi Republik Indonesia, Lembaga Negara Pengawal Konstitusi, Putusan Mahkamah Konstitusi, https://mkri.id/index.php?page=web.Putusan\&id=1\&kat=1, diunduh pada tnggal 18 Oktober 2019.

20 Emlin McClain, Dissenting Opinion, https://digitalcommons.law.yale.edu/cgi/viewcontent.cgi?article=1756\&context=yli, diunduh pada tanggal 13 November 2019. 
ditandatangani oleh para pihak. Artinya, perjanjian yang ditandatangani adalah perjanjian yang isinya disepakati oleh para pihak. Kembali ke putusan MK, hakim yang memiliki penolakan atas putusan MK tersebut tetap mendapat kesempatan terhadap pendapatnya yang bebeda dari putusan pokoknya. Ketidaksepakatannya diketik tersendiri diluar putusan MK dalam lembaran dissenting opinion. Lalu kegunaan hakim berjumlah ganjil tidak dibutuhkan. Putusan tidak diambil berdasarkan suara terbanyak. Seluruh hakim MK menandatangani satu putusan pokok yang diambil secara musyawarah. Dengan kata lain, hakim MK yang mengajukan dissenting opinion hanya menyatakan ketidaksukaannya, bukan ketidaksepakatannya yang dapat menjadi bahan pertimbangan untuk perkara yang sama berikutnya.

Dalam putusan Mahkamah Konstitusi (MK), hakim MK melakukan musyawarah untuk mencapai kesepakatan. Tentunya dengan kesepakatan tersebut, suara hakim MK akan menjadi bulat. Pemikiran logisnya, pendapat konkuren dan dissenting opinion tidak dibutuhkan, karena seluruh hakim MK telah mencapai satu suara atas putusan yang akan dibuat.

\section{Pendapat Kelompok Hakim yang Berkuasa}

Pendapat hakim MK mayoritas dalam memutus JR tidak memberikan opini lain yang beragam, karenanya concurring opinion dan dissenting opinion diperlukan. Pendapat di luar pendapat utama dapat menetralisir kekuasaan yang terlampau besar dari kelompok mayoritas hakim MK. Pendapat mayoritas hakim dapat dibagi menjadi 2 (dua), yakni: pertama, putusan MK yang merujuk kepada original intent dari UUD. Kedua, putusan MK dapat berdasarkan UUD sebagai Living Constitution. Sesuai dengan pendapat David A. Strauss yang menyatakan:

There's an even bigger problem with the living Constitution, or so it might seem. A living constitution is, surely, a manipulable constitution. If the Constitution is not constant-if it changes from time to timethen someone is changing it. And that someone is changing it according to his or her own ideas about what the Constitution should look like. The "someone," it's usually thought, is some group of judges. So a living constitution would not be the Constitution at all; in fact it is not even law any more. It is just a collection of gauzy ideas that appeal to the judges who happen to be in power at a particular time and that they impose on the rest of us.

Dalam penjelasannya, Strauss tidak menolak Living Constittution yang pengertiannya disesuaikan dengan keadaan terkini. Seperti dalam penutup bukunya, itulah Konstitusi kita yang hidup. Sangat masuk akal untuk menghormati konstitusi dan orang-orang yang bertanggung jawab atasnya. Tetapi penting untuk mengakui bahwa konstitusi adalah karya yang lebih dari sekelompok negarawan yang mendapatkan ilham. Ini adalah pekerjaan generasi manusia-pengacara dan non-pengacara, pejabat publik dan orang-orang yang menjalani kehidupan pribadi - yang 
telah bergulat dengan masalah masyarakat dan melakukan yang terbaik dan memberikan apa yang mereka telah pelajari kepada masyarakat. ${ }^{21}$

\section{Interpretasi UU antara MK dan MA yang Terintegrasi}

Peristiwa kongkrit akan diterapkan kedalam peraturan yang abstrak, termasuk UU, berdasarkan pendekatan deduktif. Setiap pasal yang terdiri dari unsur-unsur abstrak wajib terpenuhi pembuktiannya dengan unsur-unsur peristiwa kongkrit yang sama dengan unsur-unsur abstrak tersebut. Apabila unsur-unsur dalam pembuktian tidak memenuhi unsur-unsur pasal, maka peristiwanya bukanlah peristiwa hukum. Perlunya peraturan memperluas pengertian unsur-unsur abstraknya agar unsur-unsur kongkrit termasuk di dalamnya. Interpretasi sebagai cara untuk memperluas jangkauan unsur-unsur abstraknya.

Hakim MK dalam membatalkan pasal atau UU yang dibuat DPR memerlukan pendapat yang berkualitas. Seluruh hakim MK wajib memiliki kemampuan untuk menginterpretasikan UU dan UUD 1945. Tetapi MA juga memiliki hak untuk menginterpretasikan UU atas peraturan dibawah UU. Interpretasi keduanya terhadap UU dapat beririsan seluruhnya dan menjadikannya satu interpretasi. Nyatanya MA memiliki kewenangan tersendiri dalam memutus peraturan dibawah UU. Karena itu, MA perlu meinginterpretasikan UU secara mandiri.

Perbedaan sistem civil law Indonesia, sistem hukum yang dibawa oleh Belanda dan berasal dari Perancis dibandingkan dengan sistem common law Amerika. Kunci untuk memahami perbedaannya adalah bagaimana doktrin pemisahan kekuasaan beroperasi di masing-masing yurisdiksi mereka. Ada perbedaan besar dalam hal ini. Hakim common law diharapkan untuk melengkapi peraturan perundang-undangan dengan mengacu pada putusan hakim yang menjadi preseden dan disesuaikan dengan keadaan terkini untuk memahami undang-undang tersebut. Hakim civil law Perancis, di sisi lain, secara tegas menolak hal yang demikian. Hakim memiliki kewenangan hanya terbatas pada penjelasan yang dimaksud oleh legislatif. Mereka dilarang mengisi "kekosongan" dalam undang-undang hanya karena adanya kesenjangan dan pemenuhan kebutuhan undang-undang yang dimaksud agar menjadi komprehensif. Terlepas dari kenyataan bahwa ada perbedaan yang cukup besar dalam hal ini, prinsip-prinsip penafsiran menjadi dasar memperluas interpretasi terhadap undang-undang yang memiliki kesamaan. Namun, dalam penerapannya, perbedaan cenderung muncul karena peran peradilan yang sangat kontras. Tetapi setiap perbedaan itu sulit diukur mengingat singkatnya penilaian hukum dari hakim terhadap perkaranya, khususnya di dalam sistem civil law Perancis. ${ }^{22}$

Perbedaan interpretasi MK dan MA terhadap UU harus diatasi dengan pengadilan satu atap yang tidak terlepas satu dengan lainnya.

21 Ibid, hal. 137.

22 Gerard Carney, Comparative Approaches to Statutory Interpretation in Civil Law and Common Law Jurisdictions, Statute Law Review, Volume 36, Issue 1, February 2015, hal. 46-58, 
Putusan hukum MA merujuk kepada putusan yang lebih tinggi, yakni putusan MK. Putusan MK adalah putusan yang final and binding.

\section{KESIMPULAN}

Musyawarah hakim MK atas perbedaan pendapat akan membentuk satu pendapat yang absolut. Dissenting Opinion hakim MK tidak memberikan efek apapun terhadap putusan MK setelahnya. Hakim MK tersebut hanya menyatakan bahwa ia sepakat dengan putusan mayoritas hakim, akan tetapi ia memiliki pendapat yang berbeda. Dualisme ini memperlihatkan ketidakkonsitenan hakim. Putusan MK bukan putusan Supreme Court Amerika yang keterikatannya berdasarkan asas preseden. Dissenting opinion dari hakim Supreme Court memiliki kekuatan untuk mempengaruhi putusan hakim Supreme Court setelahnya.

Selain itu Putusan hakim MK akan memperbaiki penyimpangan UU terhadap UUD. Untuk dapat memutuskan UU itu menyimpang, hakim MK harus menginterpretasikan UU terlebih dahulu. Interpretasi terhadap UU yang dibuat oleh MK tidak pernah mengikat MA dalam menginterpretasikan UU. Ketidakkonsistenan interpretasi MK dan MA terhadap UU akan mempengaruhi interpretasi seluruh peraturan dibawah UU. Karena MA lebih berkuasa dalam menilai peraturan dibawah UU.

Oleh karenanya, MA dalam menginterpretasikan UU harus mengikuti putusan MK yang dibuat berdasarkan pendapat hakim MK yang utuh dan menjadi dasar yang digunakan dalam menginterpretasikan UU.

\section{Buku:}

\section{DAFTAR PUSTAKA}

Corley, Pamela C, 2010, Concurring Opinion Writing on the U.S. Supreme Court, SUNY Press, New York;

Delaney, Erin F and Rosalind Dixon, (Edited), Tom Ginsburg (Ed), 2018, Comparative Judicial Review, Cheltenham, Edward Elgar Publishing Limited, Uk dan Northampton, MA, USA;

Dimitrakopoulos, Ioannis G, 2007, Individual Rights and Liberties Under the U.S. Constitution The Case Law of the U.S. Supreme Court, Koninklijke Brill NV, Leiden;

Kamus Besar Bahasa Indonesia (KBBI), denotasi/de'no'ta'si//dénotasi/ $n$ Ling makna kata atau kelompok kata yang didasarkan atas penunjukan yang lugas pada sesuatu di luar bahasa atau yang didasarkan atas konvensi tertentu dan bersifat objektif, https://kbbi.web.id/denotasi, diunduh pada tanggal 20 Oktober 2019; 
Musyawarah, https://kbbi.web.id/musyawarah, diunduh pada tanggal 22 November 2019;

O'Neill, Cara (Ed), 2018, Legal Research, How To Find and Understand Law, The Nolo, USA;

Sloan, Amy E., 2018, Basic Legal Research: Tools and Strategies, Seventh Edition, Wolters Kluwer, New York;

Veri Junaidi, dkk, 2019, Membaca 16 Tahun Mahkamah Konstitusi (MK): Data Uji Materi Undang_undang terhadap UUD 1945 (2003-2019), Yayasan Konstitusi Demokrasi Inisiatif, Jakarta;

\section{Jurnal:}

Carney, Gerard, Comparative Approaches to Statutory Interpretation in Civil Law and Common Law Jurisdictions, Statute Law Review, Volume 36, Issue 1, February 2015;

Maulidi, M. Agus, Menyoal Kekuatan Eksekutorial Putusan Mengikat Mahkamah Konstitusi, Jurnal Konstitusi, Vol.16, No.2, Juni 2019;

MD, Moh Mahfud, Titik Singgung Wewenang MK dan MA, Jurnal Hukum dan Peradilan, Vol.4, No.1, Maret 2015;

Putra, Antoni, Dualisme Pengaturan Undang-Undang, Jurnal Legislasi Indonesia, Vol.15 No.2, Juli 2018,

\section{Internet:}

American Government, How Judges and Justices Are Chosen, https://www.ushistory.org/gov/9d.asp, diunduh pada tanggal 27 November 2019;

Fortune, The U.S. Supreme Court Will Return with Only 8 Justices, https://fortune.com/2016/09/30/us-supreme-court-justices/, diunduh pada tanggal 28 November 2019;

Jasna, Omejec, Principle of the Separation of Powers and the Constitutionla Justice System, https://bib.irb.hr/datoteka/785200.Omejec__Separation_of_Powers_and_Constitutional_Judiciary_-

_Strasbourg_28.10.pdf, diunduh pada tanggal 24 November 2019;

Keneally, Meghan, Meet All Of The Sitting Supreme Court Justices Ahead Of The New Term, https://abcnews.go.com/Politics/meet-sitting-supremecourt-justices/story?id=37229761, diunduh pada tanggal 28 November 2019;

Kompas, Yusril Pertanyakan Jumlah Hakim Konstitusi, https://nasional.kompas.com/read/2009/02/18/1106255 5/yusril.pertanyakan.jumlah.hakim.konstitusi., diunduh pada tanggal 20 Oktober 2019;

Life Science, Why Are There 9 Supreme Court Justices?, https://www.livescience.com/9857-9-supreme-court-justices.html, diunduh pada tanggal 25 November 2019; 
Mahkamah Konstitusi Republik Indonesia, Lembaga Negara Pengawal Konstitusi, Putusan Mahkamah Konstitusi, https://mkri.id/index.php?page=web.Putusan\&id=1\&kat=1, diunduh pada tanggal 18 Oktober 2019;

McClain, Emlin, Dissenting Opinion, https://digitalcommons.law.yale.edu/cgi/viewcontent.cgi?article $=17$ $56 \&$ context $=\mathrm{ylj}$, diunduh pada tanggal 13 November 2019;

Supreme Court of the United States, Opinion, https://www.supremecourt.gov/opinions/opinions.aspx, diunduh pada tanggal 28 November 2019;

Tempo.com, Tiga Langkah Bagaimana Putusan MK Dibuat, https://nasional.tempo.co/read/1259803/tarik-ulur-perpu-kpk-ini-3syarat-perpu-menurut-mk, diunduh pada tanggal 20 Oktober 2019. 